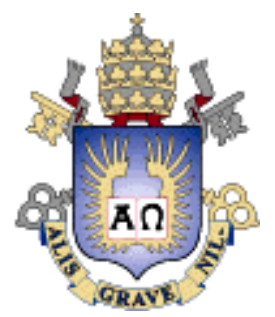

André Tadeu Santos Fialho

\title{
Transições Animadas em Aplicações Web Baseadas em Modelos
}

Dissertação de Mestrado

Dissertação apresentada como requisito parcial para obtenção do título de Mestre pelo Programa de PósGraduação em Informática da PUC-Rio.

Orientador: Daniel Schwabe 
André Tadeu Santos Fialho

Transições Animadas em Aplicações Web

Baseadas em Modelos

Dissertação apresentada como requisito parcial para obtenção do título de Mestre pelo Programa de PósGraduação em Informática da PUC-Rio. Aprovada pela Comissão Examinadora abaixo assinada.

Prof. Daniel Schwabe Orientador

Departamento de Informática - PUC-Rio

Prof. Bruno Feijó

Departamento de Informática - PUC-Rio

Profa. Simone Diniz Junqueira Barbosa

Departamento de Informática - PUC-Rio

Prof. José Eugenio Leal Coordenador Setorial do Centro

Técnico Científico - PUC-Rio

Rio de Janeiro, 30 de julho de 2007 
Todos os direitos reservados. É proibida a reprodução total ou parcial do trabalho sem autorização da universidade, do autor e do orientador.

\section{André Tadeu Santos Fialho}

Graduado em Ciência de Computação pela Universidade Federal de Lavras (UFLA) em julho de 2004. Atualmente, integra o grupo de pesquisadores do Laboratório TECWEB da PUC-Rio. Tem como principais áreas de interesse: Aplicações Hipermídia, Interação Humano-Computador e design de Interfaces.

Ficha Catalográfica

Fialho, André Tadeu Santos

Transições animadas em aplicações web baseadas em modelos / André Tadeu Santos Fialho ; orientador: Daniel Schwabe. - 2007.

133 f. : il.(col.) ; $30 \mathrm{~cm}$

Dissertação (Mestrado em Informática) - Pontifícia Universidade Católica do Rio de Janeiro, Rio de Janeiro, 2007.

Inclui bibliografia

1. Informática - Teses. 2. Animação. 3. Interfaces. 4. Transições suaves. 5. SHDM. 6. Hipermídia. I. Schwabe, Daniel. II. Pontifícia Universidade Católica do Rio de Janeiro. Departamento de Informática. III. Título. 


\section{Agradecimentos}

Primeiramente a Deus, por guiar meus passos e me permitir estar aqui.

A meus pais Romélia e Elias Fialho e a minha irmã Juliana, por acreditarem em mim, estarem sempre presentes e oferecerem apoio, exemplo, segurança e amor permanente em todos os momentos de minha vida.

A Caroline pela inspiração, carinho e os inesquecíveis momentos compartilhados.

Com grande admiração e gratidão ao meu orientador Daniel Schwabe por me apontar sempre ao horizonte, pelas oportunidades e ensinamentos que me acompanharão por toda a vida e por me passar os conhecimentos que tornaram esse projeto possível.

A Profa.Simone Diniz Junqueira Barbosa, pelos ensinamentos e contribuições que enriqueceram e ajudaram no desenvolvimento deste projeto, bem como ao Prof.Bruno Feijó pelos ensinamentos e por atender prontamente na avaliação desta dissertação.

Aos professores da Universidade Federal de Lavras, pelos ensinamentos passados e em especial ao Prof.André Zambalde, por me motivar na escolha deste mestrado.

Ao cunhado Valério, pelo companheirismo e pela segurança que me dá ao dividir a vida com a minha amada irmãzinha.

Aos companheiros e amigos da República Les Miserables, Daniel Xavier, Renato Caculé e Rodrigo Laiola, uma segunda família no Rio de Janeiro, pelos bons momentos e pela ótima experiência de convívio e amizade durante todo o período de mestrado.

A todos os colegas de mestrado, assim como todos meus amigos, em especial ao Álvaro Salgado, Mário Lúcio, Ronan Bichuett, Maíra Damasceno, Ivana Latosinski e Rodrigo Toso pelo companheirismo, apoio, churrascos e alegrias compartilhadas na cidade maravilhosa.

Ao Gilberto e a Dona Inês pelo carinho e auxílios dados durante minha vivência no Rio.

A CAPES e ao Departamento de Informática da PUC-Rio, pelas bolsas concedidas para apoio financeiro.

A todos aqueles que de alguma forma contribuíram para a concretização desta dissertação. 


\section{Resumo}

Fialho, A. T. S; Schwabe, D. Transições Animadas em Aplicações Web

Baseadas em Modelos. Rio de Janeiro, 2007. 133p. Dissertação de Mestrado - Departamento de Informática, Pontifícia Universidade Católica do Rio de Janeiro.

Apresentamos nesta dissertação uma abordagem para autoria de transições animadas em aplicações Web. As transições podem ser definidas como uma mudança de estado navegacional que resulta na alteração dos widgets e da interface. Tais alterações são, em sua maioria, representadas de forma abrupta em interfaces não animadas. O uso de animações permite uma representação gradual das transformações que ocorrem, caracterizando então, transições suaves que revelam mais claramente ao usuário a operação de navegação subjacente. A abordagem é dividida em duas etapas: Modelagem das interfaces e modelagem das transições. Na primeira etapa definimos as interfaces através da especificação de interfaces abstratas da metodologia SHDM/OOHDM. Para modelagem de transições, identificamos as animações para cada transformação e definimos através da retórica da animação: A estrutura retórica da transição, que define a seqüência de execução, e os estilos retóricos, que definem propriedades de efeitos e duração das animações. A abordagem foi implementada estendendo o ambiente de autoria hipermídia, HyperDE, possibilitando então a geração de protótipos de aplicações com transições suaves. Para execução das animações elaborou-se também uma biblioteca de transições utilizando a tecnologia Dynamic HTML. Uma avaliação preliminar com usuários demonstrou maior satisfação no uso de transições suaves e maior facilidade na interpretação de relações entre instâncias navegadas durante a interação.

\section{Palavras-chave}

Aplicações Hipermídia; Web Semântica; Ambiente de Desenvolvimento; SHDM; Animação; Interfaces; Transições Suaves. 


\section{Abstract}

Fialho, A. T. S; Schwabe, D. Animated Transitions for Web Applications

Based on Models. Rio de Janeiro, 2007. 133p. Master Science Dissertation - Department of Informatics, Pontifícia Universidade Católica do Rio de Janeiro.

In this dissertation we introduce an approach for the authoring of animated transitions in Web applications. The transitions can be defined as navigational state changes that result in the alteration of the presented widgets and interface. These alterations are usually represented abruptly through non-animated interfaces. The use of animation allows a gradual representation of the transformations that occur, characterizing a smooth transition that reveals to the user the underlying navigation operation. The approach is divided in two steps: The interface modeling and the transition modeling. In the first step, we define the interfaces through a specification of abstract interfaces provided by the SHDM/OOHDM method. In the transition modeling, we identify the animations for each transformation and define through the animation rhetorics: The transition rhetorical structure, which defines the animation execution sequence, and the rhetoric styles, that defines the effects and duration proprieties of the animation. The approach was implemented by extending the hypermedia authoring environment, HyperDE, providing smooth transitions for the generated application prototypes. In order to allow the execution of the animations, we have also developed a transition library using Dynamic HTML technology. A preliminary evaluation with users showed greater satisfaction in the use of smooth transitions and a better interpretation of the relations between navigated instances during the interaction process.

\section{Keywords}

Hypermedia Applications; Semantic Web; Development Environments; SHDM; Animation; Interfaces; Smooth Transitions. 


\section{Sumário}

1 Introdução 14

1.1. Considerações Iniciais 14

$\begin{array}{ll}\text { 1.2. Objetivos } & 16\end{array}$

$\begin{array}{ll}\text { 1.3. Estrutura do Documento } & 18\end{array}$

2 Referencial Teórico 19

2.1. SHDM 19

2.1.1. Levantamento de Requisitos 20

2.1.2. Modelagem Conceitual 20

2.1.3. Modelagem Navegacional 21

2.1.4. Modelagem de Interface Abstrata 23

2.1.5. Implementação 25

2.2. Animação 26

2.2.1. Interfaces Dinâmicas $\quad 27$

2.2.2. Vantagens no uso de Animações em Interfaces 29

2.2.3. Classificação 31

2.2.4. Efeitos de Animação 34

2.2.5. Retórica em Animações $\quad 37$

2.2.6. Padrões de Transição 42

2.2.7. Práticas para Transição 44

2.2.8. Técnicas de Animação 47

2.2.9. Tempo de Animação 50

3 Transições Animadas 52

3.1. Transições 52

3.2. Etapas da Abordagem 55

3.2.1. Modelagem da Interface 56

3.2.2. Modelagem das Transições 63

3.2.2.1. Identificação das Transições 64

3.2.2.2. Especificação das Animações de Transição 64 
3.2.2.3. Especificação da Estrutura Retórica de Transição

3.2.2.4. Especificação dos Estilos Retóricos de Transição 76

3.2.3. Interpretação da Especificação

4 Ambiente $\quad 79$

4.1. Arquitetura 81

4.2. Módulo de Interfaces 83

4.2.1. Especificação de Interfaces Abstratas 83

4.2.2. Identificação dos Widgets 88

4.2.3. Mapeamento para Interfaces Concretas 89

4.2.4. Ativação das Transições 91

4.3. Módulo de Transições 92

4.3.1. Especificação das Transições Suaves 92

4.3.1.1. Especificação das Animações 94

4.3.1.2. Especificação da Retórica de Transição 99

4.3.2. Interpretação das Transições Suaves 102

4.4. Interpretação das Animações 104

4.4.1. Definição das Estruturas 105

4.4.2. Referência à Interface Destino 105

4.4.3. Identificação das Animações 106

4.4.4. Execução das Animações 106

4.4.4.1. Funções de Animações 106

$\begin{array}{ll}\text { 4.4.5. Redirecionamento } & 108\end{array}$

4.5. Desempenho e Compatibilidade 109

5 Avaliação 110

5.1. Objetivos 110

5.2. Metodologia 110

5.3. Sistema elaborado 112

5.4. Participantes 113

5.5. Resultados 113

5.5.1. Opinião sobre a animação 113

5.5.2. Interface Estática vs. Dinâmica. 114

5.5.3. Opinião sobre o uso de transições suaves 116 
6 Conclusão 120

6.1. Contribuições 120

6.2. Avaliação dos resultados 122

6.3. Trabalhos Futuros 124

7 Referências $\quad 127$

Apêndice 1 - Roteiro de Teste 130

Apêndice 2 - Termo de Consentimento 133 


\section{Lista de figuras}

$\begin{array}{ll}\text { Figura 1 - Modelo conceitual para o domínio de filmes } & 21\end{array}$

Figura 2 - Esquema de contexto navegacional para o domínio de filmes 22

Figura 3 - Elementos que compõe a ontologia de widgets abstratos 24

Figura 4 - Análise retórica de um texto utilizando RST 39

Figura 5 - Tempo de resposta total (Bederson \& Boltman 1999) 50

Figura 6 - Transição entre nós navegacionais 53

Figura 7 - Transição suave entre interfaces distintas $\quad 55$

Figura 8 - Um esquema de contextos navegacionais para o domínio de filmes 56

Figura 9 - Widgets que compõem uma interface do contexto filmes por ordem alfabética $\quad 57$

Figura 10 - Formas de especificação de interface com a propriedade HasInterfaceElement 58

Figura 11 - Notação gráfica para representação de interfaces abstratas $\quad 59$

Figura 12 - Interface concreta para um índice de filmes $\quad 60$

Figura 13 - Interface abstrata para um índice de filmes. 60

Figura 14 - Interface concreta para um contexto de filmes por ordem $\begin{array}{ll}\text { alfabética } & 61\end{array}$

Figura 15 - Interface abstrata para o contexto filmes por ordem alfabética $\quad 61$

Figura 16 - Especificação de uma interface do contexto filmes por ordem alfabética 62

Figura 17 - Descrição de uma transição animada $\quad 67$

Figura 18 - Mudança de índice de atores para a interface atores por ordem alfabética $\quad 69$

Figura 19 - Conjunto de animações para uma transição suave $\quad 70$

Figura 20 - Transição entre interfaces distintas 71

Figura 21 - Possíveis ações para as condições de referência distintas 71

Figura 22 - Transição entre a mesma interface do contexto filmes por ordem alfabética 72

Figura 23 - Especificação de transição entre diferentes instâncias em um mesmo contexto 
Figura 24 - Exemplo de uma retórica de transição 75

Figura 25 - Exemplo de um Rhetorical Style Sheet (RHSS) 77

Figura 26 - Componentes da arquitetura do HyperDE (Nunes, 2005) 80

Figura 27 - Arquitetura do ambiente desenvolvido $\quad 82$

Figura 28 - Propriedades identificadas para os widgets de acordo com as informações definidas $\quad 84$

Figura 29 - Especificação de interface abstrata para o contexto filmes por $\begin{array}{ll}\text { ordem alfabética } & 87\end{array}$

Figura 30 - Exemplo de utilização do método Exists 88

Figura 31 - Propriedade de identificação dos widgets 89

Figura 32 - Especificação e identificação obtida no widget concreto 89

Figura 33 - Ontologia de widgets concretos implementada 90

Figura 34 - Widget concreto para mapeamento padrão 90

Figura 35 - Tela que representa a listagem das transições existentes 93

Figura 36 - Tela que representa a edição de uma transição suave 94

Figura 37 - Interfaces de uma transição entre um índice de atores para o contexto de atores por ordem alfabética 98

Figura 38 - Especificação de transição de um índice de atores para o contexto atores por ordem alfabética 99

Figura 39 - Especificação de uma estrutura retórica de transição e representação correspondente 100

Figura 40 - Efeitos de animação 101

Figura 41 - Especificação inline dos estilos retóricos 102

Figura 42 - Diagrama de seqüências representando a execução de uma

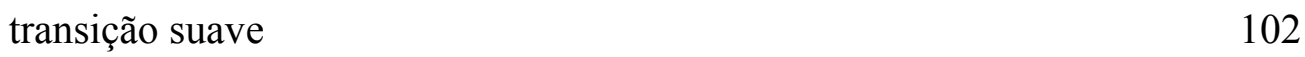

Figura 43 - Seqüência de etapas realizadas pelo interpretador de animações 105

Figura 44 - Características inseridas no sistema com Interfaces sem animação 111

Figura 45 - Características inseridas no sistema com transições suaves 112 


\section{Lista de tabelas}

Tabela 1 - Etapas da abordagem SHDM e artefatos gerados (Lima \& $\begin{array}{ll}\text { Schwabe, 2003) } & 19\end{array}$

Tabela 2 - Primitivas do modelo navegacional 21

Tabela 3 - Funções das animações associadas a perguntas que auxiliam responder 33

Tabela 4 - Atividades e artefatos da abordagem $\quad 55$

Tabela 5 - Atividades para modelagem de transições 63

Tabela 6 - Características identificadas e interações realizadas pelo usuário na utilização do protótipo sem animações 115

Tabela 7 - Características identificadas e Interações realizadas pelo usuário na utilização do protótipo com animações 116

Tabela 8 - Opiniões dos usuários quanto à atratividade, prazer e preferência de uso 